\title{
Infra-autotraduções versus supra-autotraduções: a dupla dinâmica da autotradução exemplificada pela Espanha dos séculos XV-XVI e XX-XXI ${ }^{1}$
}

\author{
Rainier Grutman* \\ Tradução de Luiz Fernando Dias Pita**
}

\begin{abstract}
A tradução, e, mais ainda, a tradução literária, apresenta-se amiúde como um trabalho ou exercício individual. Representa, para o tradutor, uma espécie de luta corpo a corpo com um texto em uma língua alheia, a qual ele trata de colocar no molde da própria língua. Através e por causa deste ato encontram-se (e enfrentam-se) dois sistemas, dos quais um é textual (el texto-fonte), enquanto o outro é linguístico (la língua de chegada). Daí uma série de tensões, ajustes e desajustes bem conhecidos dos "tradutólogos", os estudiosos da tradução. Mas, além de ser um encontro individual, esta última é também um modo de comunicação, uma forma coletiva de contato interlinguístico, uma "transferência" (EVEN-ZOHAR, 2018) intercultural. Portanto, a tradução se deixa, e até se deve, analisar com métodos que vão além da dimensão textual.

O dito acima vale também para a tradução de autor, ou autotradução, cujo contexto de produção será o enfoque das considerações seguintes.

\footnotetext{
${ }^{1}$ Este texto retoma, retoca e revisa Grutman (2011). Aproveitei a ocasião de uma publicação brasileira, graciosamente oferecida pelas professoras Alice Antunes e Marcia Martins, não só para atualizar a bibliografia, mas também para atualizar e agilizar a argumentação.

* Universidade de Ottawa, Canadá

** Instituto de Letras - ILE/UERJ
} 
Enquanto forma particular de produção escrita bilíngue (ou, se se preferir, de bilinguismo de escritura), pode-se aplicar a ela, mutatis mutandis, a famosa pergunta de Fishman (1965) para examinar quem escreve (e se traduz) em que idioma, para quem, quando, onde, com que motivos e efeitos. Ou, escolher uma língua permite identificar-se com certos grupos e situar-se em uma rede de relações, de modo que é possível descrever os motivos por trás da escolha da língua por parte de um escritor (cf. VALLVERDÚ, 1975, p. 55-71; KREMNITZ, 2004b, p. 120-177), decisão importante por ser o processo que leva a uma publicação mais longa e mais onerosa que a simples enunciação oral.

O mesmo acontece com o ato tradutório, devido ao fato de que, antes de perguntar-se como se vai traduzir, tradutores devem perguntar-se por quê o fariam. Para dizê-lo em termos de Gideon Toury (1995, p. 58-59): antes das chamadas "normas operacionais", que regem as decisões tomadas enquanto se está traduzindo, vêm as "normas preliminares". Estas últimas estão diretamente ligadas às relações entre a língua de partida e a língua de chegada. No caso da autotradução, o contato linguístico ocorre em uma só pessoa, que se torna literalmente seu "lugar geométrico por excelência2", como dizia Uriel Weinreich a propósito do locutor bilíngue em geral.

O enfoque sociolinguístico, escolhido para estas páginas, ressalta o caráter assimétrico de muitos intercâmbios linguísticos e também da (auto)tradução. Concretamente, no estudo desta última, farei duas distinções: a primeira separa uma forma "horizontal" de autotradução, de outra, "vertical", de acordo com o status das línguas implicadas. Dentro da segunda categoria, vejo duas configurações distintas, conforme a direção da transferência: rio abaixo (o que proponho chamar de infra-autotradução) ou rio acima (que chamarei de supra-autotradução).

A demonstração virá ilustrada com exemplos oriundos da bem-nutrida história da autotradução endógena no âmbito espanhol, documentada sobretudo por Julio-César Santoyo (2005, 2010, 2015). Aqui, qualifico-a como

\footnotetext{
2 “The bilingual speaker is the ultimate locus of language contact” (WEINREICH, 1953, p. 71).
} 
endógena porque se trata de um fenômeno interno do polissistema literário peninsular: ontem, tanto quanto hoje, parece dizer respeito sobretudo a suas minorias linguísticas, independentemente de fatores como o exílio (embora devamos dizer que este também produziu várias formas de escritura bilíngue, entre as quais encontra-se a autotradução ${ }^{3}$ ). Quer nós as chamemos "intraestatais" (RAMIS, 2013), pensando de modo particular na Espanha pósfranquista, ou, mais geralmente, "intrapeninsulares" (SANTOYO, 2010), a maioria das autotraduções made in Spain implicam outra série de considerações além daquelas feitas por Beckett, Nabokov ou outros "extraterritoriais" (STEINER, 1971). Em ambos os casos, autor e tradutor (que são a mesma pessoa física) podem habitar o mesmo território, mas, contrariamente aos públicos francês e britânico de Beckett, ou russo e norte-americano de Nabokov (ou francês e espanhol de Jorge Semprún, para acrescentar um exemplo hispânico), os respectivos leitores (vascófonos vs. castelhanófonos, por exemplo) dos autotradutores de Espanha nem sempre estão separados física e geograficamente, nem estavam no passado, mas se cotejavam - e continuam cotejando-se - na mesma comunidade, às vezes em uma mesma cidade.

\section{A diglossia. Um rodeio conceitual}

Foi para descrever algumas das formas múltiplas e variadas em que dois idiomas podem entrar em contato num marco social que se criou o termo "diglossia", muito menos generalizado que a tradicional palavra "bilinguismo". O DRAE4 (dle.rae.es) define como tal o "uso habitual de duas línguas em uma região ou por uma pessoa". Também em português a palavra designa ora a "situação de uma comunidade em que são faladas duas línguas", ora o "domínio de duas línguas por parte de um falante"

\footnotetext{
3 Os autotradutores migrantes ou "migratórios" (GRUTMAN, 2015) têm pouco peso, do ponto de vista estatístico (o que evidentemente não implica qualquer juízo sobre o valor estético de sua obra), contudo, inclusive considerando-se expatriados como Salvador de Madariaga, Josep Carner, Agustín Gómez Arcos ou Jorge Semprún, que acrescentaram outro idioma a seu repertório linguístico ao mudar (ou depois de mudar) de país. É de se supor que, das ondas mais recentes, não de emigração espanhola, mas de imigrações `s Espanha, sairão (ou já saíram) casos de autotradução...

4 A sigla se refere ao Diccionario de la Real Academia Española [n.t.].
} 
( https://dicionario.priberam.org/bilinguismo). Pois bem, se se pode chamar tanto dicionários quanto países (Camarões ou Canadá, Paraguai ou Porto Rico) de "bilíngues", e tanto a uma só pessoa que fala duas línguas quanto a um grupo de pessoas (uma associação profissional, um congresso científico, uma junta diretora, um conselho administrativo) cujos membros falam cada um sua língua, mas recorrem a intérpretes para passar de uma à outra, não vejo muito bem a utilidade de se continuar falando de "bilinguismo" sem maior precisão.

Nesta ordem de ideias, deve ser lembrado que não existe, fora da teoria chomskyana5, sujeito falante que domine um idioma à perfeição. Fórmulas como "equilíbrio" ou "competência nativa", que frequentemente traz consigo a etiqueta "bilíngue" aplicada a uma pessoa, escondem uma realidade sociolinguística muito mais complexa. É o que ao mesmo tempo reconhece e não quer ver Álvaro Cunqueiro quando ele se descreve como “um escritor bilíngue, no sentido mais extremo do termo. Ou seja, um bilíngue equilibrado, mas ao mesmo tempo com muitas possibilidades de interferência entre os dois idiomas", dois idiomas que considera igualmente "nativos, vernáculos" (citado por Rodríguez Vega 2017, p. 282; 2018, p. 138).

Outro problema é a extensão demasiado ampla da categoria "bilinguismo" no âmbito literário. Como há tempos assinalou Francesc Vallverdú (1975, p. 73-74),

[q]uan parlem d'escriptors bilingues solem confondre categories molt diferents de bilinguisme i apliquem aquella etiqueta a casos tan diversos com aquests:

a) escriptor que escriu alternadament en castellà i en català [u otras dois lenguas, por supuesto];

b) escriptor catalanoparlant que escriu en castellà;

\footnotetext{
5 "Linguistic theory is concerned with an ideal speaker-listener, in a completely homogeneous speechcommunity, who knows its language perfectly and is unaffected by such grammatically irrelevant conditions as memory limitations, distractions, shifts of attention and interest, and errors (random or characteristic) in applying his knowledge of the language in actual performance" (CHOMSKY, 1965, p. 3). Seu predecessor, Leonard Bloomfield, foi menos detalhista: enquanto caracterizava o bilinguismo como "native-like control of two languages", admitia que "one cannot define a degree of perfection at which a good foreign speaker becomes a bilingual: the distinction is relative" (1933, p. 56).
} 


\begin{abstract}
c) escriptor familiarmente bilingue, o castellanoparlant, que escriu alternadamente en català;

d) escriptor que en dues èpoques successives ha escrit en català i en castellà, però no pas simultaniament;

e) escriptor que escriu en català i se serveix ocasionalment (o permanentment) do castellà en um nivell no literari, purament instrumental (llengua escrita culta o vulgar).
\end{abstract}

Em sua opinião (da qual compartilho), só convém falar de “bilinguisme literari, en o sentit estricte, en els casos $a$ i $d^{\prime \prime}$ (VALLVERDÚ, 1975, p. 74), pelo menos quando falamos de literatura moderna: entende-se que o estudo de escritores do passado distante (da Idade Média ou do Renascimento, por exemplo) requer outras considerações, sobretudo pelo que se refere ao quinto caso (e), já que as bonae litterae de outrora pouco têm a ver com o que, hoje, entendemos por "literatura".

Como se pôde intuir a partir da citação de Vallverdú, os sociolinguistas costumam reservar a palavra "bilíngue" à dimensão individual. Quando se estende a grupos de locutores, segue pautas de uso linguístico ("patterns of language usage", WEINREICH, 1953, p. 71) cuja complexidade fez nascer a necessidade de uma terminologia mais precisa, principalmente em uma série importante de trabalhos a respeito da noção de "diglossia", palavra que, apesar das aparências, não é meramente a tradução grega do termo mais usual (FERNÁNDEZ, 1995), porém que se refere a uma configuração sociolinguística bem específica. Eis aqui a definição clássica proporcionada por Charles Ferguson (1959, p. 336; segundo a tradução de Linhares e Alencar (2016, p. 498):

\footnotetext{
Diglossia é uma situação linguística relativamente estável em que, além dos dialetos primários da língua (que podem incluir um padrão ou padrões regionais), há uma variedade sobreposta, muito divergente, altamente codificada (amiúde gramaticalmente mais complexa), veículo de uma grande e respeitada parcela da literatura escrita, quer de um período anterior quer de outra comunidade de fala, e que é aprendida essencialmente pela educação formal e usada para a maioria dos propósitos escritos e formais, mas não é usada por nenhum segmento da comunidade para a conversação ordinária.
} 
Em boa medida o prestígio da variedade A (por alta) deve-se ao fato de que "se aprende em sua maior parte através de uma educação formal", ou seja, que não é a fala nativa em sentido estrito; seu emprego está restrito a usos formais (escritos ou orais) e "nenhum segmento da comunidade" a considera apropriada "para a conversação ordinária", que costuma, pois, desenvolver-se na variedade B (por baja). É sobretudo por este último critério, diz Ferguson (1959, p. 336-7), que "a diglossia se distingue da relação entre uma variedade padrão e seus dialetos". Seu trabalho se baseia prioritariamente em pesquisas efetuadas no mundo de fala árabe (da qual era um especialista), com uma perspectiva comparativa proporcionada pelas situações sociolinguísticas da Suiça alemã, Grecia e Haiti. Nesses exemplos, o árabe clássico, o Schriftdeutsch, o grego katharévusa e o francês correspondem ao perfil da variedade alta, sobreposta.

Para Ferguson (1959, p. 328-9), “a especialização das funções das variedades A e B" constitui "uma das mais importantes características da diglossia", a ponto de parecer-lhe "difícil superestimar a importância de utilizar a variedade apropriada na situação apropriada". Se o indivíduo bilíngue pode passar de uma língua a outra em função de suas próprias exigências (que vão da simples comunicação à autêntica comunhão), uma alternância similar está socialmente regulada nas comunidades diglóssicas, onde a maioria dos contextos pressupõem o uso de uma língua em particular. Até o Concílio Vaticano II (1962-1965), por exemplo, em muitos países católicos, os camponeses participavam da missa em latim (sem entender muito!) enquanto falavam um dialeto às vezes substancialmente distinto da língua em que seus filhos aprendiam a ler e a escrever na escola. Além de excluir a iniciativa individual (não havia escolha na igreja, tampouco na escola), esta distribuição está baseada em um longo consenso dentro da comunidade, de maneira que a diglossia “persiste tipicamente por vários séculos" (FERGUSON, 1959, p. 332).

Esta distribuição funcional permitiu a Joshua Fishman (1967, p. 30) ampliar a noção original de diglossia “a todos os casos de uma dualidade 
funcional estável, socialmente determinada, que possam existir em uma comunidade de fala; desta maneira, ficam incluídas todas as situações de relação assimétrica entre duas línguas ou variantes, aparentadas ou não". (HAMEL; SIERRA, 1983, p. 93). Os dois sociolinguistas mexicanos que acabo de citar, Rainer Enrique Hamel e María Teresa Sierra (e outros tantos, como se pode averiguar em FASOLD, 1984, p. 34-60), consideram justificada a ampliação proposta por Fishman. Outros, contudo, entre os quais o próprio Ferguson (1991, p. 223) e Alan Hudson (2002, p. 9-19), defendem a interpretação ortodoxa mais restritiva. Preferem reservar o termo à chamada diglossia genética (que envolve duas variedades da mesma língua) e lançam mão de outro neologismo, "biglossia" (FELLMAN, 1975), na hora de caracterizar "uma situação análoga à diglossia, mas na qual as variedades Alta e Baixa pertencem a línguas diferentes" (AZURMENDI, 2002, p. 50).

Da minha parte, creio que Ferguson chamou a atenção sobre um fato fundamental: em cada comunidade linguística onde se usam regularmente dois códigos suficientemente diferentes para não serem confundidos, há uma marcada tendência a compartimentá-los e a atribuir-lhes papéis e funções não menos diferentes para serem compatíveis. Portanto, seu conceito de diglossia é algo muito distinto de um vago "bilinguismo social", ainda que, decerto, nem ele nem Fishman tenham colocado em relevo o "potencial conflitivo" (HAMEL; SIERRA, 1983, p. 95-99; KREMNITZ, 2004a, p. 162) de tais configurações omissão que o próprio Ferguson (1991, p. 227-9) haveria de reconhecer mais tarde.

\section{Diglossia e literatura}

O que têm estas considerações a ver com a literatura e com a tradução de autor? O mesmo Ferguson (1959, p. 330-1) responde à primeira pergunta, já que considerava o patrimônio literário (literary heritage) como uma qualidade intrínseca da diglossia - que se caracteriza, vale lembrar, pela existência de um corpus considerável e respeitável de literatura escrita unicamente na variedade alta. 
Ademais, vale a pena recordar que Ferguson, ao mesmo tempo em que explicitamente exclui a configuração língua padrão/dialeto de sua definição, menciona ainda, como "ilustração da utilidade de [seu] conceito" a existência paralela do latim e das "nascentes línguas românicas por um período de alguns séculos em várias regiões da Europa. A língua vernácula era usada na conversação comum, e o latim para a escrita ou em certos usos formais da língua falada. O latim era a língua da Igreja e de sua literatura, tinha prestígio e havia importantes diferenças gramaticais entre as duas variedades em cada campo etc." (FERGUSON, 1959, p. 337).

Ainda que menores, estas observações nos permitem identificar a duração do aludido período diglóssico. Assinalaria seu terminus a quo (WRIGHT, 1993, p. 379) o divórcio entre a escrita latina e a rustica romana lingua falada na época de Carlos Magno. Tal divórcio foi favorecido pela reforma do latim dirigida por Alcuíno de York, cujo afã para retornar às origens iria realçar a diferença com a língua tal como ela vinha sendo escrita desde a baixa Latinidade: “quando la grammatica e il lessico latini s'imparano più a fondo, secondo canoni ben determinati, le confusioni diventano meno frequenti, e di rimbalzo il volgare si manifesta come un modo diverso di espressione" (MIGLIORINI, 1963, p. 61).

A bem conhecida pesquisa feita por Erich Auerbach (1958, p. 177-259) sugere que se deve esperar até o princípio do século XIII para ver o aparecimento de manuscritos em língua vulgar suficientemente numerosos para poder competir com o Corpus Christianorum, quer dizer, para anular a hierarquia diglóssica criada quatro séculos antes, nos tempos de Carlos Magno. Antes do século XIII, não se encontram manuscritos inteiros, apenas trechos em língua vulgar, seja inseridos em conjuntos latinos (tal como os Juramentos de Estrasburgo ou a sequência de Santa Eulália), seja nas marginalia, as notas à margem. Auerbach (1958, p. 212-220) explica esta situação pela inexistência tanto de leitores monolíngues - as pouquíssimas pessoas capazes de ler o faziam principal ou exclusivamente em latim - quanto de mercado para este tipo de 
manuscritos, já que grande parte da nobreza feudal (fonte e agente do mecenato) era analfabeta.

Faz, pois, parte integral da definição clássica de diglossia uma forma de distinção entre o que constitui ou não a "literatura". Ferguson volta a falar de literatura quando descreve suas quatro situações exemplares. Nestas últimas, ele ressalta, “algumas poesias são compostas na variedade B [baixa] e um pequeno punhado de poetas compõe em ambas as variedades linguísticas, mas o estatuto dos dois tipos de poesia é muito distinto, no sentido de que toda a comunidade linguística sente como 'verdadeira' poesia somente a composta em A" (1959, p. 329). As obras escritas na outra variedade, menos prestigiada, podem formar parte do folclore, mas raramente serão levadas a sério. O grau de alfabetização presente nelas poderia resultar tão pouco elevado que tais autores careceriam de público. Pior ainda: poderia simplesmente não existir versão escrita com ortografia uniforme, como foi o caso das falas vernáculas na Idade Média europeia (ONG, 1984, p. 7).

Contudo, a partir do momento em que essas duas condições (imprensa e alfabetização) vão se cumprindo, as publicações em língua vulgar se tornam viáveis, e criam-se as condições para uma diglossia que já não é "cultural" (ONG, 1984), mas propriamente "literária". Na diglossia fergusoniana, só um dos dois códigos podia apresentar uma literatura. Para poder falar de diglossia literária, deve existir uma "distribuição funcional das línguas escritas" (MACKEY, 1976, p. 42; GRUTMAN, 2005; 2009b) às quais se designam terrenos ao mesmo tempo específicos e (quase) exclusivos.

Frequentemente, a linha divisória coincide com a diferença entre a criação estética (poesia, novela, teatro) e a escritura com fins mais comunicativos (prosa de ideias: ensaio, oratória, discursos e artigos jornalísticos...). Isto corresponde à quinta categoria da tipologia de Vallverdú (1975, p. 73-74). Segundo vimos, já não entra estritamente no âmbito do "bilinguismo literário" posto que a literatura de ficção se separou do conjunto do que se costumava denominar como Belas Letras. Tal restrição semântica é relativamente recente. Não vai além do século XIX, a princípios do qual a baronesa de Staël ainda podia 
aludir a toda "arte de pensar e de expressar-se" ao falar da littérature considérée dans ses rapports avec les institutions sociales (1800). Em seu tempo, a criação puramente estética era chamada "poesia" (cf. Dichtung em alemão), independentemente do gênero praticado.

Outras vezes, a diglossia parece estritamente "literária" no sentido de que a fronteira linguística corresponde a uma divisão interna do sistema literário, como a que existe entre os gêneros. Por exemplo, por estar em contato mais direto com o público que o romance, o teatro recorre mais facilmente à língua "baixa" da configuração dominada. Na Catalunha, Eduardo Mendoza rompeu com seu hábito de escrever romances em espanhol para realizar algumas peças que foram primeiro interpretadas em catalão em Barcelona. Álvaro Cunqueiro, prolífico romancista em duas línguas, parece haver reservado seu galego natal para suas obras de teatro. De modo comparável, Alfonso X de Castela ("o Sábio") havia sido ao mesmo tempo autor de obras históricas em castelhano (uma língua que não apenas reformou, mas que habilitou ao âmbito científico, jurídico e literário) e das Cantigas de Santa María em galego-português. Na Idade Média, sempre se podiam escutar poesias líricas recitadas en langue d'oc e poesias épicas em langue d'oil em certas cortes ${ }^{6}$. Tal diglossia literária ficava inclusive consignada em vários tratados trovadorescos. O catalão Raimon Vidal de Besalú, por exemplo, declarava "la lenga Lemosina" (ou seja, o occitano) sem par para a lírica, enquanto o francês lhe parecia mais adaptado para narrativas e debates poéticos como a pastorela. O próprio Dante, em seu tratado De vulgari eloquentia ( $\S \mathrm{I}, \mathrm{X}, 2-3)$, reconhece a supremacia do francês nos romances arturianos, enquanto elogia o occitano como "perfectior dulciorque" para a canção cortês (ALIGHIERI, 2011, p. 14-15).

Todas estas configurações assinalam uma alternância conforme a pautas coletivas, socialmente aceitáveis (e inclusive prescritas em artes poéticas, como acabamos de ver), de maneira que não se pode verdadeiramente falar de livre

\footnotetext{
${ }^{6}$ Foi o caso das cortes de Leonor da Aquitânia e de seus filhos (Ricardo Coração de Leão, Maria de Champanhe, Alice de França, condessa de Blois), mas também, por exemplo, no Norte da Itália, ao redor dos marqueses de Montferrato.
} 
escolha ou de livre arbítrio. No âmbito literário, a língua aponta, ainda, para uma tradição particular: a "decisão" de escrever, seja em latim ou em língua vulgar, por exemplo, sofria a intervenção de motivos práticos (de competência), estéticos (ligados à retórica, à intertextualidade), simbólicos (o prestígio do latim) e até sociais, pois atrás de cada língua se acha um público potencial, com suas expectativas e hábitos que, mesmo sendo abstratos, influem menos no escritor.

Parece tão crucial a dimensão do público, que a seu respeito formulei a hipótese seguinte: a possibilidade de escrever numa língua diferente aparece em momentos de mudança, quando se modifica a relação (simbólica ou real) entre as línguas em contato para favorecer o aparecimento de um público novo ao qual o escritor pode se dirigir (GRUTMAN, 2007, p. 33). Obviamente, o Renascimento foi um desses grandes momentos de mudança que se faz acompanhar de uma profunda reorganização do repertório linguístico, tanto no nível da planificação do corpus como do status (segundo a distinção feita por KLOSS, 1969, p. 81). Apesar de promover a volta às fontes clássicas, o humanismo acabou por favorecer as futuras línguas nacionais, seja com a "normatização" das scriptae, concebida e executada em grande parte nas academias e escolas literárias, seja pelo efeito que diversas decisões políticas tiveram em seu status - pensemos nas medidas tomadas pelos reis Francisco I, na França, ou pelos primeiros Habsburgos (Carlos I e Felipe II) na Espanha. Entretanto, esta evolução não foi isenta de problemas nem de retrocessos, já que os veículos linguísticos da nova "ragion di Stato" (expressão cunhada precisamente naquela época por Giovanni Botero) tiveram que encontrar seu caminho entre a estabilidade do latim e a relativa anarquia das falas vernáculas. Além de romper o equilíbrio diglóssico da época medieval, o Renascimento efetivou um gigantesco projeto de translatio studii, ao longo do qual se transformaram em línguas de partida (quer dizer: dignas de servir de modelo) aquelas "línguas fáceis" "que antes haviam sido sobretudo línguas de chegada,

\footnotetext{
${ }^{7}$ Como ainda as chamava Dom Quixote, na famosa passagem do Segundo Livro (cap. 62), ambientado numa gráfica de Barcelona.
} 
recipientes para o saber e a arte latinos (veja-se GRUTMAN, 2018 para exemplos concretos).

\section{Infra-autotradução e supra-autotradução}

Uma mesma dinâmica assimétrica caracteriza a autotradução (como a tradução de maneira mais geral). A noção de diglossia torna mais visíveis as transferências verticais que ocorrem no interior de uma comunidade linguística entre duas línguas de status e prestígio demasiado variáveis para que seja possível uma competição livre e leal. A autotradução evidencia, por outro lado, uma hierarquia que já não é nacional, mas internacional. Ao "mercado linguístico unificado" do Estado, "dominado pela língua oficial" (BOURDIEU, 1996, p. 53-78), corresponde a "galáxia mundial" (De SWAAN, 1991; 2001; CALVET, 1999; 2016) das línguas. São várias as metáforas, ainda que não a ideia subjacente: como na granja de Orwell ( $A$ Revolução dos Bichos), todos os animais são em princípio iguais, mas na realidade alguns são mais iguais que os outros. O peixe grande come o pequeno.

Tal como os planetas giram ao redor do sol no sistema heliocêntrico, as línguas ocupam uma posição relativa no polissistema mundial: posição bastante central para meia dúzia delas (e "hipercentral" para o inglês), enquanto a grande maioria gravita em sua órbita e ocupa posições muito menos centrais, para não dizer periféricas. Ao fim da Segunda Guerra Mundial, o inglês tornou-se o vencedor do pôquer linguístico, situação que se deve em parte ao fato de que mais de 300 milhões de pessoas o têm como fala nativa, mas também, e em grande medida, a que outros 700 milhões, que não são anglófonos, o usam como segunda língua. Este último fator é explicado não só pela hegemonia atual do inglês, mas também pelo peso menor de línguas como o árabe, o chinês ou o hindi, cujos falantes, embora numerosos, encontram-se bastante mais concentrados geograficamente e não podem contar com legiões de poliglotas para assegurar sua difusão e irradiação.

Estas diferenças entre as línguas do mundo em termos de mercado deixam marcas na forma particular de tráfego linguístico-cultural que é a 
tradução: há línguas das quais se tem traduzido muito, assim como há línguas das quais se continua traduzindo muito menos (HEILBRON, 1999). Estas diferenças também podem (embora não devessem) influir sobre a decisão de um escritor bilíngue de traduzir-se ou não.

Qualquer lista sistemática de autotradutores dá uma ideia da predominância das relações assimétricas. Observemos rapidamente o Prêmio Nobel de Literatura. Com a atribuição do prêmio a Peter Handke em 2019, são já onze os escritores, ou seja, um em cada dez premiados desde 1901, que verteram para outra língua pelo menos um de seus títulos. Eis aqui a lista (provisoriamente) completa:

Quadro 1: autotradutores vencedores do Prêmio Nobel ${ }^{8}$

\begin{tabular}{|c|c|c|c|}
\hline $\begin{array}{l}\text { Ano da } \\
\text { premiação }\end{array}$ & Nome & $\begin{array}{l}\text { L de partida > } \\
\text { L de chegada }\end{array}$ & Naturalidade \\
\hline 1904 & $\begin{array}{l}{ }^{*} \text { Frédéric Mistral } \\
(1830-1914)\end{array}$ & $\begin{array}{l}\text { occitano } \\
(\text { provençal) }> \\
\text { francês }\end{array}$ & Maillane, França \\
\hline 1913 & $\begin{array}{l}\text { *Rabîndranâth } \\
\text { Tagore (1861-1941) }\end{array}$ & bengali $>$ inglês & $\begin{array}{l}\text { Calcutá, Raj } \\
\text { Britânico (Índia } \\
\text { atual) }\end{array}$ \\
\hline 1917 & $\begin{array}{l}\text { Karl Gjellerup } \\
(1857-1919)\end{array}$ & $\begin{array}{l}\text { dinamarquês > } \\
\text { alemão }\end{array}$ & Præstø, Dinamarca \\
\hline 1934 & $\begin{array}{l}\text { Luigi Pirandello } \\
(1867-1936)\end{array}$ & $\begin{array}{l}\text { siciliano > italiano } \\
\text { e vice-versa }\end{array}$ & $\begin{array}{l}\text { Agrigento (Sicília), } \\
\text { Itália }\end{array}$ \\
\hline
\end{tabular}

8 Julio-César Santoyo (2005, p. 864) identificou os seis premiados cujos nomes vão precedidos de um asterisco. Eva Gentes encontrou Gjellerup, e os demais foram acrescentados por este seu servidor em vários trabalhos (uma análise mais detalhada se encontra em GRUTMAN, 2013). 


\begin{tabular}{|c|c|c|c|}
\hline 1966 & $\begin{array}{l}\text { Shmuel Yosef } \\
\text { Agnon (1888-1970) }\end{array}$ & iídiche $>$ hebraico & $\begin{array}{l}\text { Buchach, Galícia, } \\
\text { Império Austríaco } \\
\text { (Ucrânia atual) }\end{array}$ \\
\hline 1969 & $\begin{array}{l}\text { *Samuel Beckett } \\
(1906-1989)\end{array}$ & $\begin{array}{l}\text { inglês }>\text { francês e } \\
\text { vice-versa }\end{array}$ & $\begin{array}{l}\text { Foxrock (Dublin), } \\
\text { Irlanda }\end{array}$ \\
\hline 1978 & $\begin{array}{l}\text { *Isaac Bashevis } \\
\text { Singer (1902-1991) }\end{array}$ & iídiche > inglês & $\begin{array}{l}\text { Leoncin (Varsóvia), } \\
\text { Império russo } \\
\text { (Polônia atual) }\end{array}$ \\
\hline 1980 & $\begin{array}{l}{ }^{*} \text { Czeslaw Milosz } \\
(1911-2004)\end{array}$ & polonês > inglês & $\begin{array}{l}\text { Kèdainiai, Império } \\
\text { russo (Lituânia } \\
\text { atual) }\end{array}$ \\
\hline 1987 & $\begin{array}{l}\text { *Joseph Brodsky } \\
(1940-1996)\end{array}$ & russo $>$ inglês & $\begin{array}{l}\text { Leningrado, URSS } \\
\text { (Atualmente São } \\
\text { Petersburgo, } \\
\text { Rússia) }\end{array}$ \\
\hline 2000 & Gao Xingjian (1940) & $\begin{array}{l}\text { francês }>\text { chinês } \\
\text { (mandarim) }\end{array}$ & $\begin{array}{l}\text { Ganzhou, RP de } \\
\text { China }\end{array}$ \\
\hline 2019 & $\begin{array}{l}\text { Peter Handke } \\
\text { (1942) }\end{array}$ & francês $>$ alemão & Gissen, Áustria \\
\hline
\end{tabular}


Mesmo que se averiguasse se os autotradutores estariam superrepresentados nas cortes do Nobel (embora não se veja muito bem por que estariam), esta proporção nos convida a reavaliar certos preconceitos em relação ao caráter supostamente raro da prática autotradutora. Essa lista também evidencia seu caráter fundamentalmente assimétrico. Não quero insinuar que haja forçosamente um desequilíbrio estético entre as duas vertentes linguísticas da obra desses autores. Tampouco estou falando que, em geral, não tenham produzido a mesma quantidade de textos em cada língua. A assimetria à que me refiro tem outra causa: parte precisamente de que a tradução (e, talvez mais, a autotradução) raras vezes toma a forma de uma transferência horizontal entre idiomas de status e prestígio comparáveis, simetria que teria permitido um verdadeiro intercâmbio entre interlocutores.

Na lista acima, antes de que Handke fosse incluído, apenas Beckett parece haver operado de maneira simétrica entre duas línguas de ampla difusão e de peso comparável (o inglês e o francês continuam sendo as línguas mais lidas no mundo). Seu exemplo resulta, pois, muito menos paradigmático do que se costuma pensar (cf. GRUTMAN, 2014). O acréscimo de Handke não muda muita coisa, na verdade. Decerto, a relação entre seu alemão nativo e seu francês adotivo também pode ser qualificada como simétrica, sobretudo numa perspectiva europeia marcada pela colaboração entre Adenauer e De Gaulle, Kohl e Mitterrand. Mas tanto a posição como a postura de Handke enquanto autor nos recordam as de Beckett. O irlandês e o austríaco são ambos locutores digamos, "excêntricos", descentrados, de seus respectivos idiomas maternos. Mais ainda: a (que eu saiba) única autotradução de Handke é um monólogo dramático (Bis daß der Tag euch scheidet oder eine Frage des Lichts, 2008) que havia escrito primeiramente em francês (Jusqu'à ce que le jour vous sépare o une question de lumière, 2007) porque faz eco, e inclusive rende homenagem, a La Dernière Bande de Beckett (que é, por sua vez, uma autotradução - preparada em colaboração com Pierre Leyris - de Krapp's Last Tape, 1958). Em outras palavras, não estou convencido de que Handke teria sido traduzido se não fosse pelo modelo beckettiano. 
Os outros nove autores ( $80 \%$ ) tiveram, todos, à sua disposição dois idiomas de prestígio e peso culturais bastante desiguais, para impedir toda forma de simetria. Alguns cresceram em comunidades diglóssicas, seja no sentido estrito de Ferguson (o occitano e o francês de Mistral, o siciliano e o italiano de Pirandello), seja na acepção mais ampla de Fishman (o iídiche e o hebraico de Agnon, claro, mas não se deve subestimar o alcance do alemão na Dinamarca oitocentista de Gjellerup, ou a diglossia colonial que caracterizava o Raj britânico nos tempos de Tagore). São autotradutores "sedentários", em oposição aos autotradutores "migratórios" (GRUTMAN, 2015, p. 10-15), categoria à qual corresponde a outra metade dos premiados com o Nobel, que se puseram a escrever em duas línguas depois de sua emigração (Singer) ou exílio político (Milosz, Brodsky, Gao).

Também chama a atenção que muitos deles tenham sido traduzidos para o inglês, apesar de não ser esta sua fala nativa. Tagore recebeu o Nobel pouco depois de ter traduzido seu poemário Gitanjali do bengali à língua do império britânico (do qual era um súdito colonizado). Singer, Milosz e Brodsky eram três imigrantes que chegaram, já adultos, aos EUA vindos da Europa Oriental. Continuaram a construir uma obra já iniciada em sua língua nativa (iídiche, polonês e russo, respectivamente), da qual verteram parte para a língua de seu novo país. Pode-se conjecturar que, antes de 1989, a presença geopolítica do russo foi ainda tal que podia servir de contrapeso ao inglês de Brodsky. É, no entanto, impossível sustentar o mesmo a propósito do iídiche de Singer (idioma ao qual a Shoah desferiu um golpe fatal) e isso torna muito difícil inclusive nos casos de Milosz ou de Tagore. Apesar de o polonês e mais ainda o bengali serem falas nativas de muitíssima gente, estes escritores não tinham à sua disposição, no campo de honra da chamada "literatura universal", duas armas linguísticas cujo valor fosse igualmente reconhecido.

Uma vez constatada esta assimetria, resta distinguir entre dois tipos de autotradução, segundo a direção em que a transferência linguística se opere: rio abaixo ou rio acima. Proponho chamá-los respectivamente infra-autotradução e supra-autotradução. Talvez esta terminologia se mostre menos bárbara para 
leitores familiarizados com os estudos medievais, onde a etiqueta de "bilinguismo vertical" (ZUMTHOR, 1963, p. 29-31) designa a combinação do latim com um ou vários idiomas vernáculos, enquanto a expressão “bilinguismo horizontal" se refere às relações entre esses últimos. Gianfranco Folena aplicou a distinção ao âmbito da tradução, o que lhe levou a distinguir entre "un tradurre 'verticale', dove a lingua di partenza, di massima il latino, ha un prestigio e un valore trascendente rispetto a quella d'arrivo [...] e un tradurre 'orizzontale' o infralinguistico [...] fra lingue di struttura simile e di forte affinità culturale come le romanze" (1991, p. 13).

Se são estas as referências distantes de meu argumento, creio imprescindível aportar dois matizes. Primeiro, não me parece muito acertado, por parte de Folena, haver apresentado como sinônimos os adjetivos "horizontal" e "infralinguístico": o movimento expresso pelo prefixo infra supõe uma hierarquia e uma subordinação. Daí minha proposta de considerar a tradução infralinguística como um dos dois tipos de tradução vertical (rio abaixo), enquanto a tradução supralinguística seria, logicamente, o tipo oposto. Segundo, se não carece em absoluto de validade para a Idade Média, caracterizada, como vimos, por quatro séculos de diglossia com o latim como única língua alta frente a uma multidão de falas baixas, a ideia de uma oposição "vertical" pode estender-se a combinações de línguas escritas que não incluam o latim. Mas, mesmo se quisermos descrever épocas mais recentes, começando pelo Renascimento (STIERLE, 1996), percebemos que, à medida que o mapa geopolítico da Europa vai se complicando e a translatio imperii et studii avança, as línguas antigamente "baixas" se livram da tutela latina. Desenvolvem entre si relações de solidariedade, mas também de poder, sem passar sempre pelo latim, o que dá lugar a uma série de novas configurações, tal como as intuía Goethe desde o ano de 1827, quando cunhou o termo Weltliteratur em suas conversas com Eckermann, e tal como as pôde estudar, muito mais recentemente, Pascale Casanova, em sua análise da atual "república mundial das letras". 
Casanova (1999, p. 347-366) fala pouco de tradução, mas de maneira muito acertada. Para ela, as relações desiguais dominam o espaço literário. Ela estuda então a tradução como a via pela qual literaturas minoritárias ou minorizadas podem acumular capital simbólico (importando obras clássicas de literaturas mais prestigiosas) e como meio de consagração (numa língua mais difundida) para escritores provenientes das literaturas que Kafka chamava “pequenas" (kleine Literaturen). Em outro ensaio (CASANOVA, 2002, p. 9-10), sublinha a diferença, fundamental, em sua opinião, entre estas duas maneiras de proceder. Longe de serem duas moedas de mesma cara, são duas opções tão radicalmente distintas que seria um erro de método estudá-las juntas.

Sua observação se aplica também aos dois tipos de autotradução que acabo de distinguir. Graças à infra-autotradução (que vai rio abaixo, da língua alta à língua baixa), o autor que num primeiro momento havia publicado numa língua com mais "capital simbólico" (BOURDIEU) mantém o contato com o público de sua comunidade de origem, cuja língua se considera talvez menos prestigiosa, mas que lhe confere um selo de autenticidade. Por outro lado, mediante a supra-autotradução (que vai rio acima, da língua baixa à língua alta), o autotradutor se converte em agente e embaixador de sua própria obra numa língua que, sem ser "universal", tem maior difusão que a sua.

\section{Espanha, hoje e ontem}

A Península Ibérica nos oferece uma magnífica ilustração das ideias precedentes. Conta com uma longuíssima tradição, tanto de bilinguismo de escritura - com Ramón Llull no século XIII e Gil Vicente no século XVI como exemplos de destaque - como de autotradução propriamente dita. Esta última, como bem se sabe, conheceu um auge particular desde a morte de Franco. JulioCésar Santoyo sublinha que o fenômeno "tornou-se particularmente fértil em terras bascas, galegas e catalãs" (2005, p. 864). Ainda segundo o mesmo pesquisador, chegam a 237 (SANTOYO, 2015, p. 47) os escritores que verteram ao castelhano pelo menos um de seus textos originalmente escritos numa das línguas minoritárias da Espanha: o catalão no leste do país, o galego na zona 
fronteiriça com Portugal no oeste, o euskera ao pé e nos Pirineus do noroeste. Em cifras absolutas, o catalão é a língua de partida mais frequente: sendo usado em mais da metade dos casos documentados por Santoyo (2015, p. 50), por exemplo. Não é de se estranhar quando se sabe que seu número de falantes (um pouco mais de quatro milhões) supera facilmente a soma dos falantes de galego (1,5 milhões) e de basco (800.000). Entretanto, em valores relativos, a atividade tornou-se mais forte no País Basco, em particular desde o começo dos anos 1980.

A Associação de Escritores Bascos (Euskal Idazleen Elkartea, ou EIE) tem cerca de 380 membros, dos quais mais de uma centena (108 segundo MANTEROLA, 2018, p. 10) traduziram um de sus próprios títulos ao espanhol. Isto representa cerca de $40 \%$ de todas as traduções ao espanhol de livros em euskera: 173 títulos autotraduzidos por um total impressionante de 436 traduções (ARRULA-RUIZ, 2018, p. 91). Igualmente surpreendente é a presença de meia dúzia de autotradutores extremamente prolíficos, com mais de dez (às vezes vinte, em um caso até mesmo trinta) títulos gêmeos em seu nome (MANTEROLA, 2011, p. 124-125; ARRULA-RUIZ, 2018, p. 97). Os três primeiros desses autores (Piedad Ateka, Juan Kruz Igerabide e Mariasun Landa) escrevem literatura infantil, que é, com larga vantagem, o gênero mais autotraduzido do euskera (ARRULA-RUIZ, 2018, p. 98-99). Mas a tendência à autotradução se estende também à literatura geral: em 2011, o fenômeno editorial Bernardo Atxaga esteve pessoalmente envolvido na transferência de uma dúzia de seus títulos para espanhol (dezessete em 2018, ou seja, aproximadamente a metade de sua produção), o que o coloca na quarta posição geral, imediatamente atrás dos três nomes mencionados.

Um olhar quantitativo do âmbito catalão nos fornece resultados similares. Embora sua tese de doutoramento se concentre em um período bastante curto (1980-2015), Eva Gentes (2017, p. 82-86, 570-579), identificou 76 autotradutores, com uma produção combinada de 221 títulos autotraduzidos. Também aqui encontramos um punhado de escritores muito comprometidos: os novelistas Andreu Martin, Joan Perucho e Carme Riera elaboraram dez ou 
mais textos gêmeos tanto em catalão como em castelhano, tal como os poetas Assumpció Forcada e Joan Margarit.

Na Espanha, dito de outro modo, a autotradução não é nada "excepcional" hoje em dia, mas envolve várias dezenas de escritores. Tampouco se trata de um fenômeno "universal", entretanto, já que parece restrito a determinados setores do polissistema espanhol e configurar-se de maneiras específicas. Um fato muito notável, por exemplo, é o caráter "vertical", no sentido apontado acima, das autotraduções realizadas na Espanha pósfranquista, que vão (quase) exclusivamente do catalão, do galego ou do euskera ao castelhano, poucas vezes na direção oposta (ou, no caso basco, nunca, cf. MANTEROLA, 2011, p. 121). Não pode ser um mero acaso que a imensa maioria dos autotradutores espanhóis provenha de comunidades linguísticas não simplesmente bilíngues (o que deixaria entender que há uma simetria entre os idiomas), mas diglóssicas, caracterizadas por uma distribuição assimétrica dos dois códigos em uso (por motivos históricos conhecidos de sobra). A segunda conclusão que se pode tirar destes dados é relativa à orientação: a supraautotradução domina quantitativamente. Praticam-na, entre muitíssimos outros, o basco Bernardo Atxaga, os galegos Suso de Toro, Alfredo Conde e Manuel Rivas, os catalanófonos Maria da Pau Janer, Antoni Mari e Carme Riera. Este procedimento parece ser três vezes mais frequente que seu corolário, a infra-autotradução.

Uma preferência tão assinalada pela supra-autotradução se deve a que esta última apresenta uma forma marcada de autopromoção: oferece ao autor de uma língua de menor difusão a possibilidade (embora não a garantia) de fazer sua obra circular e ser reconhecida urbi et orbi sem ter que esperar que um tradutor o faça. Nas palavras de Ibon Uribarri (2011, p. 258): "Since the early 1980s, many writers in Basque adopted this technique, as it constituted the easiest and cheapest way to spread their work into the Spanish market". O acesso ao mercado é a face quantitativa da moeda (em termos de vendas), enquanto se pode dizer que a face qualitativa é o acesso a prêmios literários reservados à literatura em espanhol. 
Considere-se o Prêmio Planeta de romance', que é o segundo prêmio literário mais bem pago do mundo depois do Prêmio Nobel, com 601.000 euros para o ganhador e 150.250 euros para o finalista. Como é outorgado exclusivamente a livros em castelhano, já foi atribuído a autores peruanos (Mario Vargas Llosa, Alfredo Bryce Echenique), chilenos (Antonio Skármeta), colombianos (Jesús Zárate), argentinos (Marcos Aguinis), uruguaios (Antonio Larreta) e mexicanos (Jorge Zepeda Patterson), mas ficam de fora os autores das minorias linguísticas da Espanha... Exceto quando escrevem em castelhano, como foi o caso dos catalães Terenci Moix, ganhador em 1986 com No digas que fue un sueño (livro que trata dos amores de Cleópatra e Marco Antônio e que vendeu mais de um milhão de exemplares) e Maria da Pau Janer, cujo romance Pasiones romanas obteve o prêmio em 2005.

Ambos são autores bilíngues, ainda que a diferença geracional (Moix nasceu em Barcelona em 1942, Janer em Palma de Mallorca em 1966) explique distinções importantes quanto às condições históricas de seu aprendizado do espanhol (seja ao princípio, seja ao final do regime franquista). Ambos já haviam publicado em catalão quando receberam o Planeta. Porém, diferentemente de Moix, que parece haver escrito diretamente em espanhol No digas que fue un sueño, Janer (2007) diz ter seguido o exemplo de Carme Riera ao escrever seu romance nas duas línguas, retomando o texto castelhano em catalão (e também ao contrário, supomos). No entanto, dado que só a versão espanhola podia concorrer para o Planeta, o manuscrito em catalão permaneceu sem edição durante o concurso. A maiorquina havia usado do mesmo procedimento com Las mujeres que hay en mí, já finalista do Planeta em 2002, e voltou a fazê-lo em 2010, embora desta vez não mais às escondidas: Cartes que sempre he esperat e Cartas que siempre esperé foram publicados ao mesmo tempo.

Autores de línguas minoritárias, cabe sublinhar, encontram-se entre a cruz e a espada na hora de escolher entre duas opções igualmente insatisfatórias, que poderiam chamar-se "universalidade sem autenticidade" e "autenticidade

\footnotetext{
${ }^{9}$ http://es.wikipedia.org/wiki/Premio_Planeta, página consultada em 12 de novembro de 2020.
} 
sem universalidade". Se a criação original exige, desde a época romântica, certa lealdade ao idioma nativo, o desejo de ser lido por um público mais amplo "compromete o uso de uma língua materna cuja audiência é demasiado restrita" (CADUC, 1980, p. 66; cf. KREMNITZ, 2004b, p. 202-219). Ao traduzirem-se a si mesmos na língua majoritária, com toda a autoridade que a autoria supõe, os autotradutores contornan este dilema, ainda que sem anulá-lo completamente.

Porque a supra-autotradução é uma faca de dois gumes. Tanto pode aumentar a visibilidade da tradução na língua alta que pode diminuir a pertinência do original na língua baixa (GRUTMAN, 2009a; WHYTE, 2002). Pode até chegar a ocultar sua existência, como ocorre nas autotraduções que Xosé Manuel Dasilva (2013, p. 68-70) chama de "opacas" porque seu peritexto "não proporciona nenhum dado [...] que revele que se trata de uma tradução" (DASILVA, 2013, p. 112). Esta situação, que confirma a posição subalterna do idioma materno, incomoda muito aos críticos que pertencem à mesma minoria, como se pode imaginar. Daí o escândalo provocado na Catalunha pelo Prêmio Planeta de Maria da Pau Janer (PARCERISAS, 2009, p. 119-120) ou a suspeita que pesa, na Galícia, sobre a obra de Alfredo Conde, autotradutor bastante sistemático desde que ganhou o Prêmio Nacional de Literatura de Espanha por Griffón, versão espanhola de seu Xa vai o Grifón no vento. Dasilva (2013, p. 117) observa - e lamenta - a tendência de Conde de, cada vez mais, "escamotear o texto de partida em galego nas versões espanholas de seus livros". Embora não se possa falar de uma substituição linguística completa (não há abandono do idioma ancestral), esta forma de proceder (há quem diga "estratégia") privilegia uma língua com o risco de esconder a outra.

Em casos como esses, vamos nos aproximando da categoria $(b)$ de Vallverdú, ilustrada por tantos autores espanhóis - de Emilia Pardo Bazán a Camilo José Cela no âmbito galego, ou de Miguel de Unamuno a Fernando Aramburu no contexto basco - que relegaram sua fala materna à esfera oral para escrever (quase) exclusivamente na língua dominante (decerto, sendo esta a língua de sua instrução formal, não raro a dominavam tão bem ou até melhor que seu primeiro idioma cronológico). 
Outros ainda não se contentam com escrever diretamente na língua majoritária, mas se esforçam para verter suas obras posteriormente na língua de sua comunidade de origem. Graças a esta infra-autotradução, ambas as línguas se fazem visíveis em sua produção total. Estes escritores são bilíngues no sentido estrito de Vallverdú: correspondem a suas categorias $(a)$ ou $(d)$. Não sacrificam o idioma minoritário no altar da "grande" língua supostamente "universal".

Mais até que a supra-autotradução, a infra-autotradução evita que o escritor bilíngue tenha que escolher entre suas línguas. Ademais de ir rio abaixo, vai amiúde da língua culta aprendida à fala nativa: pouco frequente na Espanha de hoje, foi, contudo, adotada séculos antes por muitos autotradutores ativos no campo das letras neolatinas. É pelo menos a hipótese que me inspiram os utilíssimos trabalhos panorâmicos sobre a autotradução nos séculos XV e XVI, realizados por Alan Deyermond (1992) e Julio-César Santoyo (2003). Se combinamos suas listas, chegamos a uma colheita de 38 autotradutores ativos como tais entre 1417 e 1695. Cronologicamente, vai do notório Enrique de Villena (autor da primeira tradução da Eneida em língua vulgar) ao desconhecido pregador Josep Romaguera. Tratam-se geralmente de experiências isoladas. São muito poucos os eruditos que, à maneira de Alonso Fernández de Madrigal (Tostatus Abulensis) e Alfonso de Palencia no século XV (DEYERMOND, 1992, p. 144-148) ou Martín de Azpilcueta no século seguinte (SANTOYO, 2003, p. 18-21), desenvolveram uma atividade autotradutora constante. Às vezes, a tarefa foi encomendada por uma autoridade secular ou eclesiástica: Isabel, a Católica, no caso de Nebrija, a Inquisição no de frei Luís de León (SANTOYO, 2003, p. 4-5, 21-22).

Não nos causarão surpresa as línguas envolvidas nestas autotraduções, nem a direção da maioria delas: 27 de 38 escritores (71\%) verteram um de seus próprios textos para e sobretudo do latim (são 19 os exemplos deste último tipo, ou seja, exatamente a metade do corpus). O latim não é, claro, a única língua de partida. Pelo menos nove autores assim avaliam o castelhano digno de servir de nova plataforma interlinguística. Chama particularmente a atenção seu papel como língua de partida para autotraduções para o basco: uma vez que naquela 
época muitos bascos desconheciam o castelhano, obviamente, mas também com claros motivos de proselitismo (que, vale lembrar, de São Jerônimo a Eugene Nida foi e continua sendo o maior impulso para traduzir). Também se converte em língua de chegada do grego, do português (D. Pedro de Portugal) e do catalão (Enrique de Villena), todos idiomas politicamente subalternos ao castelhano "compañero del imperio" (Nebrija).

Na Espanha dos Reis Católicos e dos primeiros Habsburgos dominavam, pois, as infra-autotraduções. Curiosamente, foram feitas numa proporção exatamente inversa ${ }^{10}$ à que observamos acima, a propósito das supraautotraduções na Espanha pós-franquista. São tão marcadas as duas tendências, e é tão grande a diferença entre elas, que não se pode atribuir à iniciativa ou às preferências pessoais dos indivíduos bilíngues envolvidos no processo. Os motivos pelos quais decidiram escrever primeiro em uma determinada língua e logo traduzir-se para tal outro idioma são coletivos, quer dizer, obedecem a pautas compartilhadas em suas comunidades respectivas.

$\mathrm{O}$ afã humanista por infra-autotraduzir-se tem uma explicação relativamente simples: escreveram em latim, a língua de sua formação intelectual, simplesmente porque não eram capazes de escrever textos da mesma índole em sua língua nativa, que amiúde carecia de conceitos abstratos e dos termos para expressá-los. Entretanto, a decisão de "vulgarizar" (ou seja, literalmente, transpor para a locutio vulgaris) seus tratados redigidos em latim é uma maneira de contestar a supremacia histórica do douto idioma, contestação ainda impensável na Idade Média e que testemunha a importância novamente adquirida pelas futuras línguas nacionais. Ao mesmo tempo, por sua mera existência, a infra-autotradução assinala que a escritura em língua vulgar não era ainda completamente autônoma com respeito ao latim: a autêntica autonomia suporia a possibilidade de escrever diretamente na língua baixa, sem passar pelo latim.

\footnotetext{
${ }^{10}$ Se somadas as infra-autotraduções a partir do castelhano (9) às que têm o latim (19) como língua de partida, chega-se a 28 num total de 38 , ou quase $74 \%$.
} 
A preferência moderna pela supra-autotradução indica que este dilema foi superado, já que poder traduzir-se ao idioma majoritário pressupõe que exista um texto-fonte na língua menos difundida. Mas indica também que a decisão de fazer carreira nesta última (decisão facilitada pelo impulso combinado do romantismo e do nacionalismo) não tem somente vantagens, segundo os próprios escritores. Quando manejam com igual facilidade a língua majoritária, não querem renunciar ao acesso a mercados simbólica e economicamente mais atrativos, de maneira que, de algum modo, a supraautotradução também termina confirmando a configuração diglóssica e levando a juízo a autonomia da literatura produzida na língua minorizada.

\section{Conclusão}

As páginas precedentes evidenciam fatos que convém recapitular. Em primeiro lugar, que a autotradução não é um fenômeno idiossincrático, mas que se inscreve numa dinâmica sociocultural mais ampla. Além da competência linguística individual dos autotradutores, está intimamente ligada às relações mutáveis de solidariedade e de poder entre as línguas usadas em suas respectivas comunidades. Sendo estas relações o que são, em muitos lugares do mundo (não só na Espanha), torna-se impossível fugir à questão da assimetria, que não por acaso é um traço compartilhado por todas as definições de diglossia. Intervém também outro fator: à diferença da tradução "normal", a autotradução ocorre tanto dentro de uma mesma sociedade quanto entre duas sociedades distintas, o que costuma implicar uma transferência internacional ou, pelo menos, intercomunitária. Após distinguir - terceira observação - entre a autotradução de tipo horizontal e a de tipo vertical aqui estudada, convém estudar-se, dentro desta última categoria, a direcionalidade (rio abaixo ou rio acima?) já que este é um índice sumamente importante do sentido e do valor da decisão, por parte de um autor já não simplesmente bilíngue, mas diglóssico, de traduzir a si mesmo. 


\section{Referências}

ALIGHIERI, Dante. De vulgari eloquentia / Sobre a eloquência em vernáculo. Edição bilíngue; tradução, introdução e notas de Tiago Tresoldi; prefácio de Henrique Sagebin Bordini. Porto Alegre: Tiago Tresoldi Editore, 2011 [1305?].

ANTUNES, Maria Alice; GRUTMAN, Rainier (eds.). Tradução em Revista 16. Número temático Autotradução/Self-Translation. Rio de Janeiro, 2014.

Disponível em https://www.maxwell.vrac.pucrio.br/rev_trad.php?strSecao=fasciculo\&fas=27149\&numfas=16. Último acesso: 01 nov. 2020.

ARACIL, Lluís V. Papers de sociolinguística. Barcelona: La Magrana, 1982.

ARRULA-RUIZ, Garazi. Autoitzulpenaren teoria eta praktika Euskal Herrian/Theory and Practice of Self-translation in the Basque Country. Tese de doutorado - Universidad del País Vasco, Vitoria-Gasteiz, 2018.

AUERBACH, Erich. Literatursprache und Publikum in der lateinischen Spätantike und im Mittelalter, Bern: Francke, 1958.

AZURMENDI, Maria-Jose. Comentarios. International Journal of the Sociology of Language, 157, p. 49-58, 2002.

BLOOMFIELD, Leonard. Language. New York: Henry Holt, 1933.

BOURDIEU, Pierre. A economia das trocas linguísticas: o que falar quer dizer. Trad. Sergio Miceli et al. São Paulo: Editora da USP, 1996.

CADUC, Éveline. L'écrivain face à sa langue d'expression. Culture française, 29, 1, p. 64-72, 1980.

CALVET, Louis-Jean. Pour une écologie des langues du monde. Paris: Plon. 1999.

CALVET, Louis-Jean. Fundamentos de uma ecologia das línguas. In: COUTO, Hildo Honório do; COUTO, Elza Kioko Nakayama Nenoki do; ARAÚJO, Gilberto Paulino de; ALBUQUERQUE, Davi Borges de (eds.), O paradigma 
ecológico para as ciências da linguagem: ensaios ecolinguísticos clássicos e contemporâneos. Universidade Federal de Goiás, Editora CEGRAF/ UFG, 2016.

CASANOVA, Pascale. La République mondiale des Lettres, Paris, Seuil. En portugués: A República Mundial das Letras. Trad. Marina Appenzeller. São Paulo: Estação Liberdade, 2002 [1999].

CASANOVA, Pascale. Consécration et accumulation de capital littéraire. La traduction comme échange inégal. Actes de recherche en sciences sociales, 144, 3, p. 7-20, 2002.

CHOMSKY, Noam A. Aspects of the Theory of Syntax. Cambridge, MA: M.I.T. Press, 1965.

DASILVA, Xosé Manuel. Estudios sobre la autotraducción en el espacio ibérico. Berna: Peter Lang, 2013.

DASILVA, Xosé Manuel; TANQUEIRO, Helena (eds.) Aproximaciones a la autotraducción. Vigo: Academia do Hispanismo, 2011.

DE SWAAN, Abram. Notes on the emerging global language system: regional, national and supranational. Media, Culture and Society, 13, p. 309-323, 1991.

DE SWAAN, Abram. Words of the World: the global language system. Cambridge: Polity Press, 2001.

DEYERMOND, Alan. Notas sobre diglosia literaria e autotraducción en el siglo XV hispánico. Miscellanea Antverpiensia, Homenaje al vigésimo aniversario del Instituto de estudios hispánicos de la Universidad de Amberes (Eds. Nelson Cartagena; Christian Schmitt). Tubingen: Niemeyer, p. 135-157, 1992.

EVEN-ZOHAR, Itamar. Tradução e transferência. Trad. Juliana Steil. Ipotesi Revista de Estudios Literários, 22, 2, p. 73-78, 2018. Disponível em: https://periodicos.ufff.br/index.php/ipotesi.

FASOLD, Ralph. The Sociolinguistics of Society. Oxford: Blackwell, 1984.

FASOLD, Ralph. The Sociolinguistics of Language. Oxford: Blackwell, 1990.

FELLMAN, Jack. On diglossia. Language Sciences, 34, p. 38-39, 1975. 
FERGUSON, Charles A. Diglossia. Word, 15, p. 325-340, 1959.

FERGUSON, Charles A. Diglossia revisited. Southwest Journal of Linguistics, 10, p. 214-234, 1991.

FERNÁNDEZ, Mauro. Bilingüismo y diglosia. Verba, 5, p. 375-391, 1978.

FERNÁNDEZ, Mauro. Los orígenes del término diglosia: historia de una historia mal contada. Historiographia Linguistica, 22, 1-2, p. 163-195, 1995.

FERRARO, Alessandra; GRUTMAN, Rainier (eds.). L'Autotraduction littéraire : perspectives théoriques. Paris: Classiques Garnier, 2016.

FISHMAN, Joshua A. Who Speaks What Language to Whom and When? La Linguistique, 1, 2, p. 67-88, 1965.

FISHMAN, Joshua A. Bilingualism with and without diglossia; diglossia with and without bilingualism. Journal of Social Issues, 23, 2, p. 29-38, 1967.

FOLENA, Gianfranco. Volgarizzare e tradurre. Torino: Einaudi, 1991.

GENTES, Eva. (Un-)Sichtbarkeit der literarischen Selbstubersetzung in der romanisch-sprachigen Gegenwartsliteratur. Eine literatur- und ubersetzungssoziologische Annäherung. Tese (Doutorado), Heinrich-HeineUniversität, Düsseldorf, 2017.

GRUTMAN, Rainier. Auto-translation. In: BAKER, Mona (ed.). Routledge Encyclopedia of Translation Studies. London/New York: Routledge, p. 17-20, 1998.

GRUTMAN, Rainier. Diglossie littéraire. In: BENIAMINO, Michel; GAUVIN, Lise (eds.). Vocabulaire des études francophones: les concepts de base. Limoges: Presses Universitaires de Limoges, p. 59-62, 2005.

GRUTMAN, Rainier. L'écrivain bilingue et ses publics: une perspective comparatiste. In: GASQUET, Axel; SUAREZ, Modesta (eds.). Écrivains multilingues et écritures métisses. L'hospitalité des langues. ClermontFerrand: Presses Universitaires Blaise Pascal, p. 31-50, 2007. 
GRUTMAN, Rainier. La autotraducción en la "galaxia" de las lenguas. Quaderns, 16, p. 123-134, 2009a․

GRUTMAN, Rainier. Writing and reading diglossia: evidence from the Frenchspeaking world. In: MORENO, Carolina Amador; NUNES, Ana (eds.). The Representation of the Spoken Mode in Fiction: how authors write how people talk. Lewiston, NY: The Edwin Mellen Press, p. 13-40, $2009 \mathrm{~b}$.

GRUTMAN, Rainier. Diglosia e autotraducción vertical (en y fuera de España). In: DASILVA, Xosé Manuel; TANQUEIRO, Helena (eds.). Aproximaciones a la autotraducción. Vigo: Academia do Hispanismo, p. 69-91, 2011.

GRUTMAN, Rainier. A sociological glance at self-translation (and selftranslators). In: CORDINGLEY, Anthony (ed.). Self-translation: Brokering Originality in Hybrid Culture. London: Bloomsbury, p. 63-80, 2013.

GRUTMAN, Rainier. Beckett: a quintessência da autotradução? (trad. Bianca Walsh e Simone Vieira Resende). Tradução em Revista, 16, p. 1-11, 2014. Disponível em: https://www.maxwell.vrac.pucrio.br/rev_trad.php?strSecao=fasciculo\&fas=27149\&numfas $=16$

GRUTMAN, Rainier. Francophonie et autotraduction. Interfrancophonies, 6, p. 1-17, 2015. Disponível em: www.interfrancophonies.org.

GRUTMAN, Rainier. Autotraducción, autoría e autopromoción en el Siglo de Oro: las posturas de Juan de Mariana e Bernardino Gómez Miedes. Quaderns, 25, p. 143-163, 2018.

HAMEL, Rainer Enrique; SIERRA, María Teresa. Diglosia y conflicto intercultural: la lucha por un concepto o la danza de los significantes. Boletín de Antropología Americana, 8, p. 89-110, 1983.

HEILBRON, Johan. Towards a Sociology of Translation. Book Translations as a Cultural World-System. European Journal of Social Theory, 2, 4, p. 429-444, 1999.

HUDSON, Alan. Outline of a theory of diglossia. International journal of the sociology of language, 157, p. 1-48, 2002. 
JANER, Maria da Pau. La traducció és el nostre taló d'Aquilles. Avui, p. 8-9, 29 mar 2007.

KLOSS, Heinz. Research Possibilities on Group Bilingualism: A Report. Québec: Centre International de recherche sur le bilinguisme (CIRB-ICRB), Université Laval, 1969.

KREMNITZ, Georg. Diglossie: possibilités et limites d'un terme. Lengas, 11, 22, p. 199-213, 1987.

KREMNITZ, Georg. Diglossie - Polyglossie. In: AMMON, Ulrich; DITTMAR, Norbert; MATTHEIER, Klaus J.; TRUDGILL, Peter (eds.). Soziolinguistik. Ein internationales Handbuch zur Wissenschaft von Sprache und Gesellschaft, vol. 1 / 1, Berlin: Walter de Gruyter, p. 158-165, 2004a.

KREMNITZ, Georg. Mehrsprachigkeit in der Literatur. Wie Autoren ihre Sprachen wählen. Wien: Praesens, 2004b.

LINHARES, Miguel Afonso; ALENCAR, Claudiana Nogueira de. Repensando o conceito de diglossia à luz de Michel de Certeau. Revista de Estudos da Linguagem, v. 24, n. 2, p. 492-518, 2016.

MACKEY, William F. Langue, dialecte et diglossie littéraire. In: GIORDAN, Henri; RICARD, Alain (eds.). Diglossie et littérature. Bordeaux-Talence: Maison des sciences de l'Homme d'Aquitaine, p. 19-50, 1976.

MANTEROLA AGIRREZABALAGA, Elizabete. La autotraducción en la literatura vasca. In: DASILVA, Xosé Manuel; TANQUEIRO, Helena (eds.). Aproximaciones a la autotraducción. Vigo: Academia do Hispanismo, p. 111140, 2011.

MANTEROLA AGIRREZABALAGA, Elizabete. Self-Translation from a Diglossic Perspective: The Reality of the Basque Country. Testo e Senso (Roma), n. 19, 2018. Disponível em: http://testoesenso.it/

MIGLIORINI, Bruno. Storia della lingua italiana. Firenze: Sansoni, 1963.

ONG, Walter J. Orality, Literacy, and Medieval Textualization. New Literary History, 16, 1, p. 1-12, 1984. 
PARCERISAS, Francesc. De l'asymétrie au degré zéro de l'autotraduction. Quaderns, 16, p. 117-122, 2009.

RAMIS, Josep Miquel. La autotraducción y el difícil encaje de sistemas literarios en contacto. Eu-topías, 5, p. 99-111, 2013.

RODRÍGUEZ VEGA, Rexina. Diglosia e autotradución, cara a construción dun novo imaxinario da lingua. In: LÓPEZ, Teresa; MALINGRET, Laurence; FEIJÓ, Elias J. Torres (eds.) Estudos literarios e campo cultural galego. En honra do profesor Antón Figueroa. Universidade de Santiago de Compostela: Cadernos CIPPC, p. 273-286, 2017.

RODRÍGUEZ VEGA, Rexina. Autotraducción y biliterariedad en el espacio ibérico. El caso gallego. Quaderns, 25, p. 133-142, 2018.

SANTOYO, Julio-César. De Nebrija a Sor Juana Inés da Cruz: apuntes someros para una historia das traducciones de autor (autotraducciones) en España y Portugal, 1488-1700. In: SABIO PINILLA, José Antonio; VALENCIA, María Dolores (eds.). Seis estudios sobre a traducción en los siglos XVI y XVII: España, Francia, Italia, Portugal. Granada: Comares, p. 1-49, 2003.

SANTOYO, Julio-César. Autotraducciones: una perspectiva histórica. Meta, 50, 3, p. 858-867, 2005.

SANTOYO, Julio-César. Autotraducciones intrapeninsulares: motivos históricos, razones actuales. In: GALLÉN, Enric; Francisco LAFARGA; Luis PEGENAUTE (eds.). Traducción y autotraducción en las literaturas ibéricas. Berna: Peter Lang, p. 365-380, 2010.

SANTOYO, Julio-César. Consideraciones acerca del estatus actual de la autotraducción en la Península Ibérica. Glottopol 25, p. 47-58, 2015.

STEINER, George. Extraterritorial: Papers on Literature and the Language Revolution. New York: Atheneum, 1971.

STIERLE, Karlheinz. Translatio Studii and Renaissance: From Vertical to Horizontal Translation. In: BUDICK, Sanford; ISER, Wolfgang (eds.). The Translatability of Cultures: Figurations of the Space Between. Stanford, CA: Stanford University Press, p. 55-67, 1996. 
TOURY, Gideon. Descriptive Translation Studies and Beyond. Philadelphia: John Benjamins, 1995.

URIBARRI ZENEKORTA, Ibon. Dialectics of opposition and construction: Translation in the Basque Country. In: ASIMAKOULAS, Dimitris: ROGERS, Margaret (eds.). Translation and Opposition. Bristol-BuffaloToronto: Multilingual Matters, p. 247-264, 2011.

VALLVERDÚ, Francesc. L'escriptor català i el problema da llengua. Barcelona: Edicions 62, 1975.

WEINREICH, Uriel. Languages in Contact: Findings and Problems. New York: Linguistic Circle, 1953.

WHYTE, Christopher. Against Self-Translation. Translation and Literature 11.1, p. 64-71, 2002.

WRIGHT, Roger. Complex monolingualism in early Romance. In: ASHBY, William J.; MITHUN, Marianne; PERISSINOTTO, Giorgio; RAPOSO, Eduardo (eds.). Linguistic perspectives on the Romance languages (LSRL, XXI), Philadelphia: John Benjamins, p. 377-388, 1993.

ZUMTHOR, Paul. Langue et techniques poétiques à l'époque romane (XI-XIII siècles). Paris: Klincksieck, 1963. 